\title{
New data about Chiropterofauna of the "Monte Pellegrino" Nature Reserve (Palermo, Italy)
}

\author{
Marta Lo Nigro ${ }^{1}$, Angelica Rallo ${ }^{1, *}$, Giovanni Provinzano ${ }^{2}$, Elena Vanisova $^{3}$, and Mario \\ Lo Valvo ${ }^{1}$ \\ ${ }^{1}$ Dipartimento di Scienze e Tecnologie Biologiche, Chimiche e farmaceutiche, Via Archirafi 18, I- \\ 90123 Palermo, Italy \\ ${ }^{2}$ Rangers d'Italia, Sezione Sicilia, Viale Diana, Cancello Giusino, 90146, Palermo, Italy \\ ${ }^{3}$ Peoples' Friendship University of Russia (RUDN University), 117198, Miklukho-Maklaya str., 6, \\ Moscow, Russia
}

\begin{abstract}
This work increase the knowledge related to bat fauna present in the "Monte Pellegrino" Nature Reserve in the Palermo municipality. The acoustic sampling took place in the summer/autumn season using the D500X Bat detector in 22 samples. The identified signals were attributed to 8 species and one genus. The Taxa with the most passes in the reserve are: Tadarita teniotis followed by Pipistrellus kuhlii, Hypsugo savii $(100 \%$ of Costancy), Pipistrellus pygmaeus, Pipistrellus pipistrellus, Plecotus sp., Miniopterus schreibersii and last with a single recording Rhinolophus ferrumequinum and Rhinolophus hipposideros. The dendrogram of similarity shows 3 distinct bats cenosis. Two samples present intense activity in almost all time slots and three samples, close to each, show a peak increase in the intermediate time slots for the three most abundant species. The analysis carried out on the environmental preferences shows that among the 13 Corine Land Cover (CLC) habitats, the highest number of passes is recorded in Artificial lakes (code 5122), Orchards (code 222) and Arid limestone grassland (code 3211). The Arid limestone grassland habitat (code 3211) has the highest Shannon Index value, while the Mastic stain habitat (code 32312) has the lowest diversity value. The dendrogram of similarity shows two clusters. In the first there are Gorse (code 32231), Mediterranean scrub (code 31111), Orchards (code 222), Mosaic of agricultural plots (code 242), while the second cluster contains the remaining habitats.
\end{abstract}

\section{Introduction}

Sicily is the largest island in the Mediterranean and has a great variety of habitats. Despite this, the data and knowledge related to Chiropterofauna are few and fragmented.

Nowadays the checklist of bats of the Sicilian territory includes 24 species [1]. Only recently Gaisler's long-eared bat Plecotus gaisleri [2] is added to the list for the island of Pantelleria bringing the number of bats species in the Sicilian Region to 25. The most

\footnotetext{
*Corresponding author: angelicarallo@gmail.com
} 
recent studies, although scarce in numbers, took place in almost all the provinces of the Sicily [3-6], however, there are still many gaps and further studies are needed.

The lack of data both from a systematic, physiological and ecological point of view is due to the objective difficulties encountered in the detection of bats species and above all in the direct observation of their individuals, to their nocturnal habits, the wide home-range, and the difficulty of identifying individuals in flight [7].

\section{Study Area}

The research was carried out within the "Monte Pellegrino" Nature Reserve established in 1996. It covers about 1,050 hectares and it is 606 meters a.s.1.. The mountain is a carbonate massif and is a real ecological island. it is surrounded both by Palermo city and by the sea and therefore exchanges with the external fauna are few. There is a high biodiversity with rare and endemic Taxa of both plants and animals [8] like the Sicilian Green Toad (Bufotes boulengeri siculus). This species is present with large population in the Pond of Santa Rosalia, the only temporary wetland area of the reserve [9].

Today, also due to anthropization, the vegetation cover of the mountain has seen a significant reduction in the scrub and holm oak forest. The species that characterize them are Quercus ilex, Euphorbia dendroides, Chamaerops humilis and Ampelodesmos mauritanicus. Furthermore, numerous reforestation works have been carried out consisting of alien forest species such as Pinus halepensis, Eucalyptus gomphocephala and E. camaldulensis and Cupressus arizonica [10]. Much of the vegetation cover of the undergrowth of the summit plateau is made up of the thorny Galactites tomentosa. There are also other non-native species such as Opuntia ficusindica, Agave americana and Pennisetum setaceum which dominate on the southern side of the mountain.

\section{Materials and Methods}

Acoustic sampling took place in the summer/autumn months from 22 July to 10 October 2020 on discontinuous days, in a total of 21 stations. To these was added a further sample in May 2020 that is in the Pond of Santa Rosalia (sample 1), in the presence of water (the same sample was also examined in the summer/autumn period without water, sample 7) raising the number of bioacoustic samples to 22 . Bats communities were studied using Pettersson's D500X Bat detector [11, 12], designed for passive monitoring. A range of time was given with sunset activation and sunrise shutdown. The Bat detector stayed on for an average of 10 hours for each night. The geographical coordinates and altitude of the sampling sites were detected with GPS.

All recordings, each lasting 5s, were analysed using BatExplore 2.1.7.0 and BatSound 4.4 software in Time Expantion x10. For proper identification, the indications of Russo and Jones [13] and Barataud [14] were followed. In some cases, in order to avoid errors of identification, mainly due to the overlapping of certain frequencies, the classification has been 1) attributed at the genus level (e.g. Plecotus sp.); or 2) assigned to the pair of species (Pipistrellus kuhlii/Pipistrellus pipistrellus); or 3) defined as indeterminate.

To describe the bats community the analyses were based on the number of bats passes of the different Taxa per stations. In order to assess the bats' habitat preferences, statistical analyses were conducted using the Corine Land Cover (CLC) habitats Map of Sicily (scale 1: 50,000), within the boundaries of the reserve. With the help of the ArcGIS 10.2 software, the portions of habitat falling within a buffer of 250 around sampling points have been cropped, detecting the characteristics of the habitats and their surfaces falling in the 
selected areas (Fig. 1). To standardize the results, the number of total passes for Taxon was divided by the number of samples which then fell into the different Corine Land Cover (CLC) habitat. The use of Past 4.05 software has allowed us to perform all the analyses.

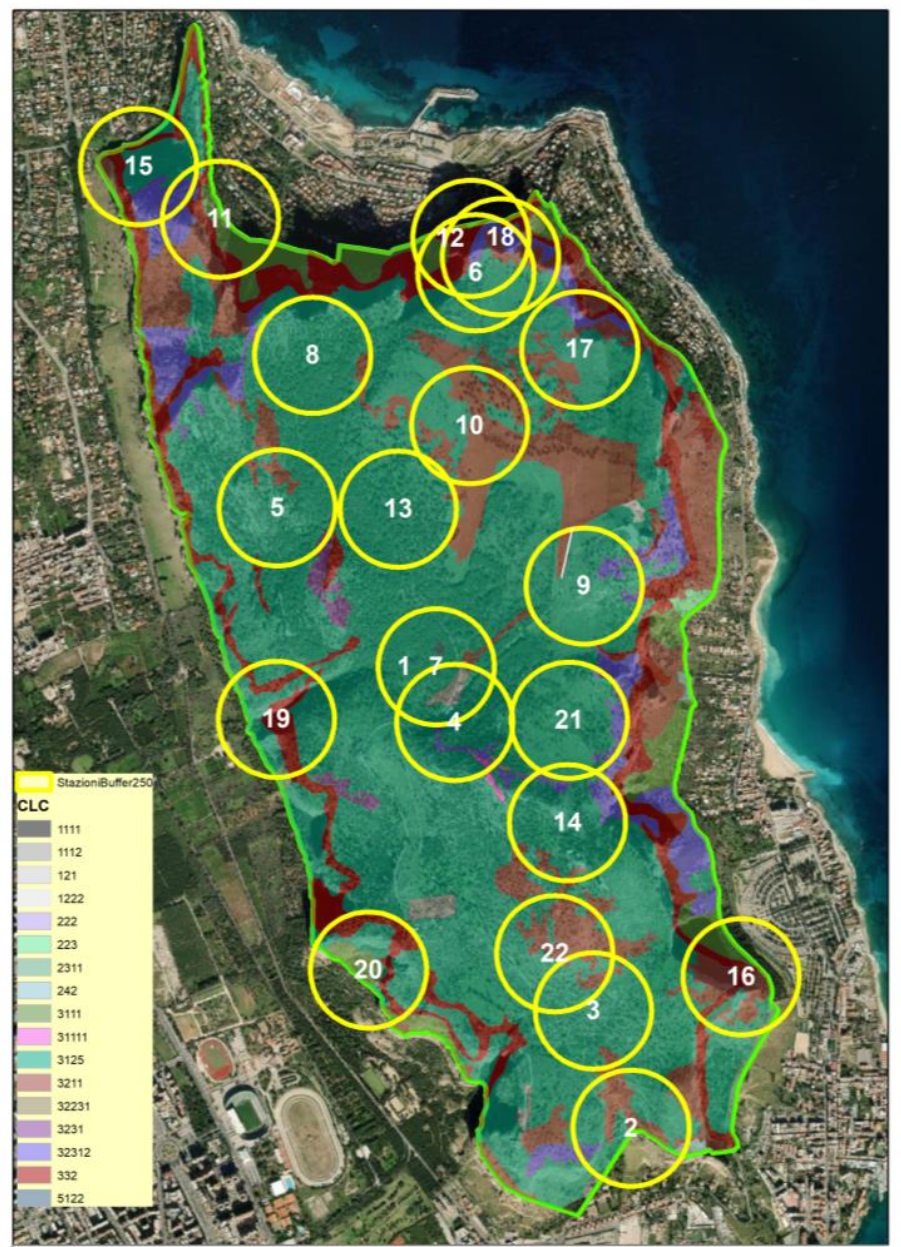

Fig. 1. The "Monte Pellegrino" Nature Reserve with its 21 stations of sampling. Habitat types for Corine Land Cover (CLC) codes are shown in Table 5.

\section{Results}

\subsection{Analyses of Presences}

We have collected 9,277 recordings with 12,979 total contacts. The signals analysed were identified and attributed to 11 Taxa of which 8 at the species level, 1 only attributed to the genus level and 2 uncertain (Table 1). 
Table 1. Taxa identified in the "Monte Pellegrino" Nature Reserve.

\begin{tabular}{|l|l|}
\hline \multicolumn{1}{|c|}{ Scientific Name } & \multicolumn{1}{c|}{ English Name } \\
\hline Rhinolophus ferrumequinum & Greater horseshoe bat \\
\hline Rhinolophus hipposideros & Lesser horseshoe bat \\
\hline Pipistrellus kuhlii & Kuhl's pipistrelle \\
\hline Pipistrellus pipistrellus & Common pipistrelle \\
\hline Pipistrellus pygmaeus & Soprano pipistrelle \\
\hline Hypsugo savii & Savi's pipistrelle \\
\hline Plecotus sp. & Long-eared bat \\
\hline Miniopterus schreibersii & Common bent-wing bat \\
\hline Tadarita teniotis & European free-tailed bat \\
\hline
\end{tabular}

The analyses are carried out both taking into account all samples (Table 2) and taking into account only those where the taxon is present (Table 3).

Table 2. Taxa. The table takes into account all the samples.

\begin{tabular}{|l|c|c|c|c|c|c|}
\hline \multicolumn{1}{|c|}{ Taxa } & $\begin{array}{c}\text { Total bat } \\
\text { pass es }\end{array}$ & $\begin{array}{c}\text { n. of } \\
\text { samples }\end{array}$ & Average & Std. & Max & Min \\
\hline P. kuhlii & 4068 & 22 & 184,91 & 13,60 & 881 & 1 \\
\hline H. savii & 1765 & 22 & 80,23 & 8,96 & 496 & 1 \\
\hline T. teniotis & 6778 & 22 & 308,09 & 17,55 & 1383 & 5 \\
\hline P. pipistrellus & 68 & 22 & 3,09 & 1,76 & 28 & 0 \\
\hline Plecotus sp. & 62 & 22 & 2,82 & 1,68 & 22 & 0 \\
\hline P. pygmaeus & 137 & 22 & 6,23 & 2,50 & 134 & 0 \\
\hline R. ferrumequinum & 1 & 22 & 0,05 & 0,21 & 1 & 0 \\
\hline R. hipposideros & 1 & 22 & 0,05 & 0,21 & 1 & 0 \\
\hline M. schreibersii & 10 & 22 & 0,45 & 0,67 & 10 & 0 \\
\hline P. kuhlii-P. pipistrellus & 78 & 22 & 3,55 & 1,88 & 24 & 0 \\
\hline Indeterminate & 11 & 22 & 0,50 & 0,71 & 4 & 0 \\
\hline
\end{tabular}

Table 3. The table takes into account only the samples in which the Taxon is present.

\begin{tabular}{|l|c|c|c|c|c|c|}
\hline \multicolumn{1}{|c|}{ Taxa } & $\begin{array}{c}\text { n. of } \\
\text { samples }\end{array}$ & Costancy & Average & Std. & Max & Min \\
\hline P. kuhlii & 22 & 100 & 184,91 & 13,60 & 881 & 1 \\
\hline H. savii & 22 & 100 & 80,23 & 8,96 & 496 & 1 \\
\hline T. teniotis & 22 & 100 & 308,09 & 17,55 & 1383 & 5 \\
\hline P. pipistrellus & 8 & 36,36 & 8,50 & 2,92 & 28 & 2 \\
\hline Plecotus sp. & 14 & 63,64 & 4,43 & 2,10 & 22 & 1 \\
\hline P. pygmaeus & 3 & 13,64 & 45,67 & 6,76 & 134 & 1 \\
\hline R. ferrumequinum & 1 & 4,55 & 1,00 & 1,00 & 1 & 1 \\
\hline R. hipposideros & 1 & 4,55 & 1,00 & 1,00 & 1 & 1 \\
\hline M. schreibersii & 1 & 4,55 & 10,00 & 3,16 & 10 & 1 \\
\hline P. kuhlii-P. pipistrellus & 13 & 59,09 & 6,50 & 2,55 & 24 & 1 \\
\hline Indeterminate & 6 & 27,27 & 1,57 & 1,25 & 4 & 1 \\
\hline
\end{tabular}


The table 2 shows the analyses carried out on the number of bat passes for Taxon taking into account each sample even when a Taxa was not present. The Taxa with the most passes in the reserve are: T. teniotis followed by $P$. kuhlii, H. savii, P. pygmaeus, $P$. pipistrellus, Plecotus sp., $M$. schreibersii and last with a single recording $R$. ferrumequinum and $R$. hipposideros. Uncertain calls have been attributed to $P$. kuhlii/P. pipistrellus and indeterminate. The analyses in the table 3 , on the other hand, take into consideration only the samples in which the Taxon is present. It can be seen that the 3 dominant species with 100\% Constancy Index are always T. teniotis, P. kuhlii and $H$. savii found in all samples. Based on the number of bat passes, the Shannon Diversity Index was calculated. The mean Shannon Index value for samples is 0.95 ( \pm 0.26 ; range 0.26-1.22). The dendrogram of similarity, built from Morisita Index in Fig. 2, shows that in the reserve the similarity between the 22 different samples is $65 \%$, and there are 3 distinct bats cenosis.

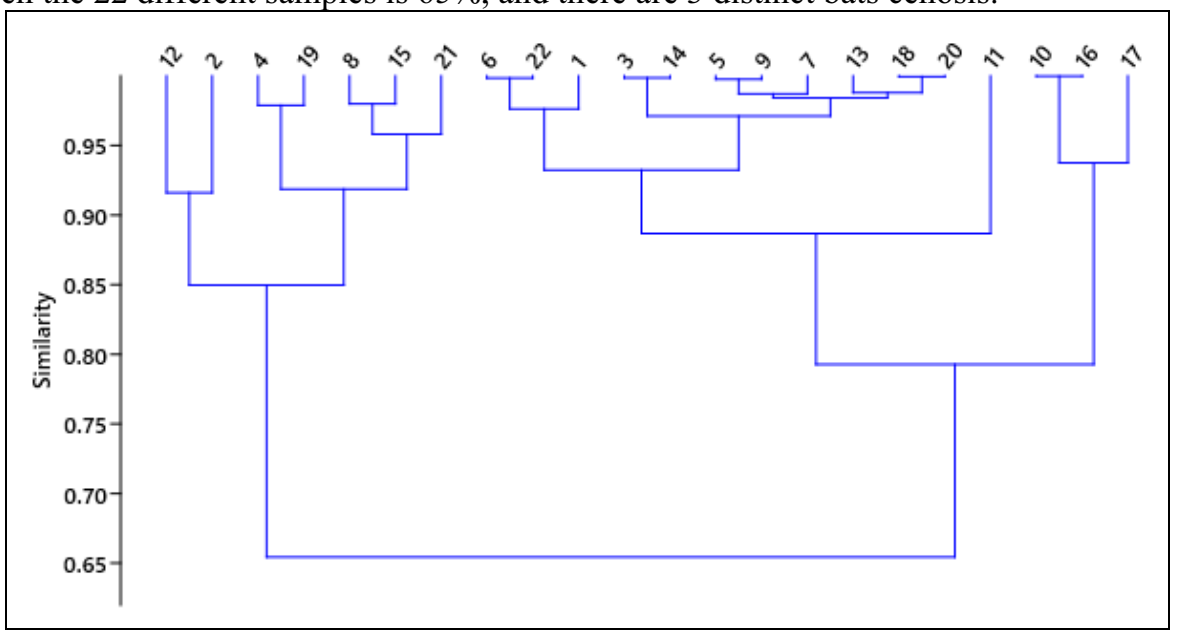

Fig. 2. Dendrogramm of Morisita similarity between 22 bioacoustic samples.

For each sample, the total number of passes for each time slot has been counted since the first exit of the first Taxon at each sample to understand the time when bats have the most activity (Table 4).

Table 4. Samples of interest as regards the number of bats passes for each time slot.

\begin{tabular}{|c|c|c|c|c|c|c|c|}
\hline 1 & P. kuhlii & H. savii & T. teniotis & $\mathbf{1 8}$ & P. kuhlii & H. savii & T. teniotis \\
\hline 20:12-21:11 & 52 & 44 & 59 & $19: 30-20: 29$ & 87 & 42 & 95 \\
\hline 21:12-22:11 & 39 & 15 & 210 & $20: 30-21: 29$ & 60 & 12 & 52 \\
\hline 22:12-23:11 & 23 & 11 & 130 & $21: 30-22: 29$ & 74 & 6 & 84 \\
\hline 23:12-00:11 & 27 & 1 & 240 & $22: 30-23: 29$ & 9 & 4 & 70 \\
\hline $00: 12-01: 11$ & 17 & 3 & 115 & $23: 30-00: 29$ & 73 & 19 & 92 \\
\cline { 6 - 9 } $01: 12-02: 11$ & 34 & 4 & 182 & $00: 30-01: 29$ & 108 & 45 & 124 \\
\hline $02: 12-03: 11$ & 28 & 1 & 103 & $01: 30-02: 29$ & 77 & 17 & 97 \\
\hline $03: 12-04: 11$ & 53 & 1 & 95 & $02: 30-03: 29$ & 125 & 3 & 129 \\
\hline $04: 12-05: 11$ & 37 & 2 & 72 & $04: 30-04: 29$ & 109 & 13 & 117 \\
\hline $05: 12-06: 11$ & 27 & 0 & 0 & $05: 30-06: 29$ & 144 & 1 & 116 \\
\hline
\end{tabular}




\begin{tabular}{|c|c|c|c|c|c|c|c|c|c|c|c|}
\hline 9 & P. kuhlii & H. savii & . teniotis & $\mathbf{1 4}$ & P. kuhlii & H. savii & T. teniotis & $\mathbf{2 1}$ & $\boldsymbol{P .}$ kuhlii & H. savii & T. teniotis \\
\hline 20:21-21:20 & 0 & 5 & 19 & $20: 00-20: 59$ & 36 & 19 & 61 & $18: 52-19: 51$ & 32 & 62 & 78 \\
\hline $21: 21-22: 20$ & 1 & 2 & 5 & $21: 00-21: 59$ & 72 & 44 & 126 & $19: 52-20: 51$ & 25 & 34 & 23 \\
\hline $22: 21-23: 20$ & 0 & 6 & 11 & $22: 00-22: 59$ & 102 & 67 & 174 & $20: 52-21: 51$ & 16 & 9 & 5 \\
\hline $23: 21-00: 20$ & 2 & 4 & 10 & $23: 00-23: 59$ & 161 & 32 & 178 & $22: 52-22: 51$ & 55 & 113 & 32 \\
\hline $00: 21-01: 20$ & 0 & 1 & 4 & $00: 00-00: 59$ & 134 & 70 & 147 & $23: 52-00: 51$ & 55 & 56 & 29 \\
\hline $01: 21-02: 20$ & 67 & 13 & 73 & $01: 00-01: 59$ & 22 & 28 & 43 & $00: 52-01: 51$ & 126 & 53 & 95 \\
\hline $02: 21-03: 20$ & 121 & 28 & 140 & $02: 00-02: 59$ & 5 & 2 & 27 & $01: 52-02: 51$ & 169 & 41 & 132 \\
\hline $03: 21-04: 20$ & 39 & 2 & 54 & $03: 00-03: 59$ & 11 & 4 & 29 & $02: 52-03: 51$ & 116 & 49 & 99 \\
\hline $04: 21-05: 20$ & 2 & 0 & 16 & $04: 00-04: 59$ & 0 & 1 & 15 & $03: 52-04: 51$ & 93 & 33 & 46 \\
\hline $05: 21-06: 20$ & 1 & 0 & 8 & $05: 00-05: 59$ & 1 & 1 & 45 & $05: 52-05: 51$ & 4 & 0 & 3 \\
\hline
\end{tabular}

Of interest are samples 1 and 18 that have intense activity in almost all time slots and the group of samples 9, 14, 21 close to each other showing a peak increase in the intermediate time slots for the 3 most aboundant species.

\subsection{Habitat Preferences}

An analysis was carried out on the habitat preferences to verify how much environmental diversity influences the diversity of the bat community, based on the different Taxa and the number of passes for each taxon. The results obtained on the basis of the aggregation of habitats found in the 22 samples are reported below (Table 5).

Table 5. Average of the number of total bat passes in the Corine Land Cover (CLC) habitats in the "Monte Pellegrino" Nature Reserve.

\begin{tabular}{|c|c|c|c|c|c|c|c|c|c|c|c|c|c|}
\hline Taxa & $\begin{array}{c}222- \\
\text { Orchards }\end{array}$ & $\begin{array}{c}\mathbf{2 4 2}- \\
\text { Mosaic of } \\
\text { agricultural } \\
\text { plots }\end{array}$ & $\begin{array}{c}332 \text { - Bare } \\
\text { rocks, } \\
\text { cliffs, } \\
\text { outcrops }\end{array}$ & $\begin{array}{c}1112 \text { - } \\
\text { Residential } \\
\text { areas }\end{array}$ & $\begin{array}{c}2311 \text { - } \\
\text { Uncultivate } \\
\mathrm{d}\end{array}$ & $\begin{array}{c}3111 \text { - } \\
\text { Holm } \\
\text { oads } \\
\text { woods }\end{array}$ & $\begin{array}{c}3125- \\
\text { Reforestatio } \\
\mathrm{n} \text { of } \\
\text { conifers }\end{array}$ & $\begin{array}{c}3211 \text { - Arid } \\
\text { limestone } \\
\text { grasslands }\end{array}$ & $\begin{array}{c}\text { 3231 - } \\
\text { Thermop } \\
\text { hilic stain }\end{array}$ & $\begin{array}{c}\mathbf{5 1 2 2}- \\
\text { Artificial } \\
\text { lakes }\end{array}$ & $\begin{array}{c}31111 \text { - } \\
\text { Mediterran } \\
\text { ean scrub }\end{array}$ & $\begin{array}{c}32231 \text { - } \\
\text { Gorse }\end{array}$ & $\begin{array}{c}32312- \\
\text { Mastic } \\
\text { stain }\end{array}$ \\
\hline P. kuhlii & 26,00 & 30,00 & 223,07 & 189,75 & 22,00 & 217,00 & 189,10 & 166,37 & 15,00 & 221,50 & 286,00 & 151,00 & 285,31 \\
\hline H. savii & 15,00 & 69,00 & 92,93 & 101,25 & 9,00 & 58,33 & 84,00 & 65,95 & 3,00 & 47,50 & 243,00 & 101,00 & 174,00 \\
\hline T. teniotis & 5,00 & 18,00 & 270,57 & 354,25 & 173,00 & 282,83 & 316,86 & 312,63 & 24,00 & 677,50 & 44,00 & 79,00 & 365,85 \\
\hline P. pipistrellus & & & 1,36 & 12,25 & & 0,83 & 3,24 & 3,21 & & 10,50 & 28,00 & 2,00 & 5,38 \\
\hline P. austriacus & 1,00 & 1,00 & 2,43 & 6,00 & 1,00 & 2,50 & 2,95 & 2,53 & & 11,50 & & & 4,23 \\
\hline P. pygmaeus & & & 0,14 & 33,75 & & & 6,52 & 7,21 & & 67,50 & & & 10,38 \\
\hline R. ferrumequinum & & & & 0,25 & & & 0,05 & 0,05 & & 0,50 & & & 0,08 \\
\hline R. hipposideros & & & & & & & 0,05 & 0,05 & & & & & \\
\hline M. schreibersii & & & & 2,50 & & & 0,48 & 0,53 & & 5,00 & & & 0,77 \\
\hline P. kuhlii-P. pipistrellus & 1,00 & & 2,43 & 10,50 & 0,50 & 2,00 & 3,71 & 4,00 & & 18,00 & 6,00 & 10,00 & 5,23 \\
\hline Indeterminate & 1,00 & & 0,50 & 1,00 & 0,50 & 0,17 & 0,52 & 0,47 & 1,00 & 2,00 & & 2,00 & 0,69 \\
\hline
\end{tabular}

The table 6 shows the Sum of averages of bat passes per taxon, number of taxa $(\mathrm{N})$, Average over averages of bat passes for taxon, maximum (Max) and minimum (Min) number of passes per taxon.

Table 6. Sum of averages of bat passes per taxon, number of Taxa $(\mathrm{N})$, Average over averages of bat passes for taxon, maximum (Max) and minimum (Min) number of passes per taxon. The codes refer to the habitats in Table 5 .

\begin{tabular}{|l|c|c|c|c|c|c|}
\hline $\begin{array}{c}\text { Corine Land } \\
\text { Cover (CLC) } \\
\text { codes }\end{array}$ & $\begin{array}{c}\text { Sum of } \\
\text { averages } \\
\text { of bat } \\
\text { passes }\end{array}$ & $\begin{array}{c}\text { N. of } \\
\text { taxa }\end{array}$ & $\begin{array}{c}\text { Average } \\
\text { over } \\
\text { averages of } \\
\text { bat passes }\end{array}$ & Std. & Max & Min \\
\hline $\mathbf{1 1 1 2}$ & 49 & 6 & 8,17 & 2,86 & 26 & 1 \\
\hline $\mathbf{2 4 2}$ & 118 & 4 & 29,50 & 5,43 & 69 & 1 \\
\hline $\mathbf{3 1 2 5}$ & 593 & 8 & 74,18 & 8,61 & 271 & 0 \\
\hline $\mathbf{3 2 1 1}$ & 712 & 10 & 71,15 & 8,44 & 354 & 0 \\
\hline
\end{tabular}




\begin{tabular}{|l|c|c|c|c|c|c|}
\hline $\mathbf{3 2 3 1 2}$ & 206 & 6 & 34,33 & 5,86 & 17 & 1 \\
\hline $\mathbf{3 1 1 1 1}$ & 564 & 7 & 80,52 & 8,97 & 28 & 0 \\
\hline $\mathbf{3 2 3 1}$ & 608 & 11 & 55,23 & 7,43 & 317 & 0 \\
\hline $\mathbf{3 3 2}$ & 563 & 11 & 51,18 & 7,15 & 313 & 0 \\
\hline $\mathbf{3 1 1 1}$ & 43 & 4 & 10,75 & 3,28 & 24 & 1 \\
\hline $\mathbf{5 1 2 2}$ & 1062 & 10 & 106,15 & 10,30 & 678 & 1 \\
\hline $\mathbf{3 2 2 3 1}$ & 607 & 5 & 121,40 & 11,02 & 286 & 6 \\
\hline $\mathbf{2 3 1 1}$ & 345 & 6 & 57,50 & 7,58 & 151 & 2 \\
\hline $\mathbf{2 2 2}$ & 852 & 10 & 85,19 & 9,23 & 366 & 0 \\
\hline
\end{tabular}

Among the Corine Land Cover (CLC) habitats, the highest number of passes is recorded in the habitat Artificial lakes (code 5122), Orchards (code 222) and Arid limestone grassland (code 3211), followed by Thermofilic stain (code 3231), Gorse (code 32231), Mediterranean scrubs (code 31111) and Baree rocks, cliffs, and outcrops (code 332). The Taxa are present in each Corine Land Cover (CLC) habitat with average values for taxon varying between 121,40 passes in Gorse (code 32231) and 8,17 passes in Residential areas (code 1112).

Shannon diversity index is calculated basing on the Corine Land Cover (CLC) habitats. The average Shannon Index for samples is 1.08 ( \pm 0.18 ; range 0.32 and 0.71$)$ (Table 7).

Table 7. Shannon Index ( $\left.\mathrm{H}^{\prime}\right)$ of Corine Land Cover (CLC) habitats. The codes refer to the habitats in

\begin{tabular}{|c|c|c|c|c|c|c|c|c|c|c|c|c|c|}
\hline $\begin{array}{c}\text { Corine Land } \\
\text { Cover (CLC) } \\
\text { habitats }\end{array}$ & $\mathbf{1 1 1 2}$ & $\mathbf{2 4 2}$ & $\mathbf{3 1 2 5}$ & $\mathbf{3 2 1 1}$ & $\mathbf{3 2 3 1 2}$ & $\mathbf{3 1 1 1 1}$ & $\mathbf{3 2 3 1}$ & $\mathbf{3 3 2}$ & $\mathbf{3 1 1 1}$ & $\mathbf{5 1 2 2}$ & $\mathbf{3 2 2 3 1}$ & $\mathbf{2 3 1 1}$ & $\mathbf{2 2 2}$ \\
\hline $\mathbf{H}^{\prime}$ & 1,17 & 0,99 & 1,08 & 1,33 & 0,58 & 1 & 1,12 & 1,1 & 0,97 & 1,13 & 1,1 & 1,22 & 1,21 \\
\hline
\end{tabular}

The Arid limestone grassland habitat (code 3211) has the highest diversity value, while the Mastic stain habitat (code 32312) has the lowest diversity value.

The Fig. 3 shows the dendrogram of similarity between Corine Land Cover (CLC) habitats.

Fig. 3. Dendrogram of Morisita similarity between Corine Land Cover (CLC) habitats.

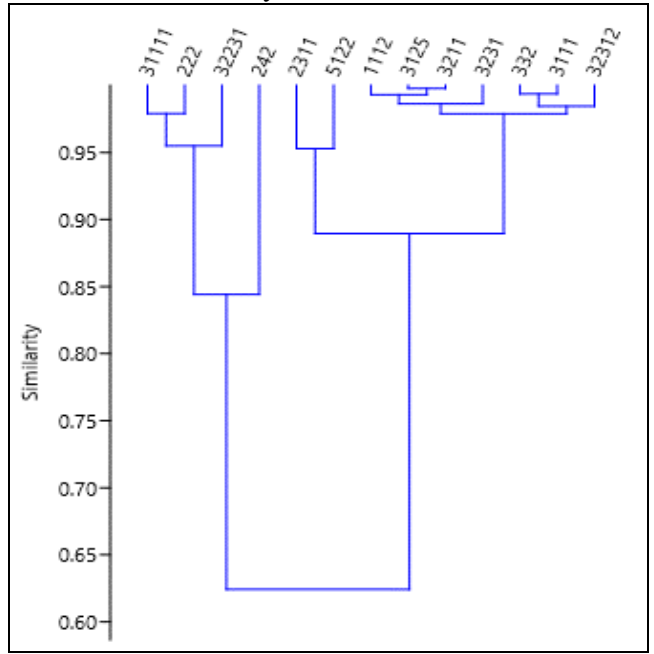


Quantitatively, the Morisita overlap Index and the dendrogramm of similarity between the Corine Land Cover (CLC) habitats show two clusters that differ in a similarity value of approximately 63\%. In the first there are Gorse (code 32231), Mediterranean scrub (code 31111), Orchards (code 222), Mosaic of agricultural plots (code 242), while the second cluster contains the remaining habitats.

\section{Discussion}

The information regarding Chiropterofauna present in the "Monte Pellegrino" Nature Reserve is to be attributed in the past to Zava and Catalano [15] regarding the presence of $T$. teniotis and the presence of $R$. ferrumequinum $[16,17]$. A more recent study also mentions $P$. kuhlii, P. pipistrellus and H. savii [18].

This study, in addition to confirming the presence of these Taxa, adds: the species $P$. pygmaeus, M. schreibersii, R. hipposideros and the genus Plecotus.

The soprano pipistrelle, P. pygmaeus, only after 2014 [19] became part of the Sicilian checklist as a cryptic species with $P$. pipistrellus [20] and genetically separated in 1997 [21]. As for Plecotus, in Sicily (excluding P. gaisleri in Pantelleria) this genus includes $P$. auritus and $P$. austriacus, both morphological and bioacustic cryptic species [22, 23]. Taking into consideration the ecological aspects of the two species, it may be Plecotus austriacus. The only way for proper classification is capture with an integrated analysis of biometrics and acoustic signals.

The rarest species like $R$. ferrumequinum and $R$. hipposideros were found with only one recording each. This is given by the emission intensity of the ultrasound of the two species which is very low like $5 \mathrm{~m}$ of detection range while for example $T$. teniotis has a very strong intensity of emission of ultrasound with $150 \mathrm{~m}$ of detection range. As a result, some Taxa can be overestimated while others are decidedly under-represented [14].

The sample that has high richness is the first "Gorgo of S. Rosalia" in spring. The reason is due to the presence of water. The pound is one of the very few watering points available to animals in reserve and for bats it is also a high source of food. In fact, $T$. teniotis was present in almost all recordings with multiple individuals having frequencies in disorder for crowding and reflection of ultrasound on the surface of the body water. In the absence of this in the summer/autumn season the number of Taxa has decreased as well as the relative Dominance of those present.

The 3 Clusters obtained with the Morisita Index shows the presence of 3 groups of environmental typology of Chiroptera in the reserve. This can be given by the greater heterogeneity of environments associated with a different ratio in the number of passes and Taxa numbers per station.

As regards the group of samples 9, 14, 21 which are next to each other and face the east side of the reserve, forming a dell that hugs the cemetery of Rotoli downstream, and which include the highest point at $606 \mathrm{~m}$ above sea level, there is a simultaneous increase in the number of passes in the intermediate time slots of P. kuhlii, H. savi and T. teniotis. The hypothesis is that this part of the east side of the mountain may represent mainly an area suitable for foraging while in the summer/autumn season the Gorgo of S. Rosalia (samples 1/7) is without water. Of course, further studies are needed to be able to verify this.

Considering the analysis made on habitat preferences, the results obtained show that the species T. teniotis, $P$. kuhlii and $H$. savii frequent all the habitats of the reserve. This confirms their characteristic of being ubiquitous, in agreement with Russo and Jones [24] 
according to which the three species are generalist and have a strong synanthropic character. $P$. pipistrellus, according to the results obtained from the statistical analysis relating to the Corine Land Cover (CLC) habitats, seems to prefer the Mediterranean scrub habitat, recording the highest average number of total passes in this habitat. Analysing the results relating to the $P$. pygmaeus and $M$. schreibersii species and the Plecotus genus, it is clear that these Taxa prefer the Artificial lakes habitat.

The Shannon Index shows the highest diversity in terms of Taxa in the Arid limestone grassland habitat, but the habitat positively selected by the largest number of Taxa contacted is the aquatic habitat. The reason could be the presence of greater trophic biomass, in accordance with Di Salvo's theory of the lake-effect [25], in fact the average number of total passes for each taxon was recorded in the census carried out in spring, the moment of flood and maximum explosion of vegetation.

\section{Conclusion}

In conclusion, it can be said that this study has been a great success. It allowed to draw up the checklist of the protected area. The next step will be to focus on implementing appropriate catch plans and through the study of biometrics with the contribution of new acoustic matter it will be possible to have a much clearer picture of the Chiropterofauna of the "Monte Pellegrino" Nature Reserve. In this way it will be possible to take another step to understand what is the distribution of bat fauna in the Sicilian territory.

\section{References}

1. A. Fulco, M. Lo Valvo, III Convegno Italiano sui Chirotteri, Trento, 9-11 ottobre 2015 (Gruppo Italiano Ricerca Chirotteri-Associazione Teriologica Italiana, 2015)

2. L. Ancillotto, L. Bosso, S. Smeraldo, E. Mori, G. Mazza, M. Herk, A. Galimberti, F. Ramazzotti, D. Russo, Ecol. Evol., 10 (2020)

3. A. Fulco, M. Vattano, P. Valenti, G. Madonia, M. Lo Valvo, III Convegno Italiano sui Chirotteri, Trento, Abstracts, 30 (Gruppo Italiano Ricerca Chirotteri, Roma, 2015)

4. I. Di Salvo, D. Russo, M. Sarà, Hystrix It. J. Mamm., 20 (2009)

5. I. Di Salvo, A. Fulco, M. Sarà, Hystrix, It. J. Mamm (n.s.) Supp. (2012)

6. M. Mucedda, G. Fichera, E. Pidinchedda, III Convegno Italiano sui Chirotteri, Trento, 9-11 ottobre 2015 (Gruppo Italiano Ricerca Chirotteri-Associazione Teriologica Italiana, 2015)

7. M. Borrello, Effetti della composizione in uso del suolo sulla ricchezza in specie della chirotterofauna. Università degli Studi di Napoli Federico II, 201072011, Russo D.: 6 (2011)

8. M. Lo Valvo (red.), Naturalista sicil., 10 (suppl.) (1986)

9. M. Lo Valvo, G. Giacalone, Annali Museo Civico Storia Naturale di Ferrara, 6 (2003): 61-65 (2003)

10. A. Di Martino, F.M. Raimondo, Webbia, 34 (1979)

11. R.T. Trubitt, T.J. Hovick, E.H Gillam, D.A. McGranahan, Ecol Evol., 9 (2019)

12. P. Stahlschmidt, C. Brühl, Methods in Ecology and Evolution, 3 (2012)

13. D. Russo, G. Jones, J. of Zool., 258 (2002)

14. M. Barataud, Acoustic ecology of European bats. Species Identification and Studies of Their Habitats and Foraging Behaviour. Second edition (Biotope Editions, Mèze; National Museum of Natural History, Paris (collection Inventaires et biodiversité), 2020) 
15. B. Zava, E. Catalano, Mammalia, 48 (1984)

16. B. Zava, A. Corrao, E. Catalano. Chirotteri cavernicoli di Sicilia. $9^{\circ}$ congreso internacional de espeleologia, Vol. II (Barcelona, Spain, 1986)

17. B. Zava. La fauna delle grotte del Palermitano. Da "Le grotte del Palermitano" (1986)

18. I. Di Salvo, M. Sarà, VII Confresso Italiano Teriologia (2010)

19. G. Fichera, M. Mucedda, P. Catalano, E. Pidinchedda, Biodiversity J., 4 (2014)

20. D. Russo, G. Jones, Mammalia, 64 (2000)

21. E.M. Barratt, R. Deaville, T.M. Burland, M.W. Bruford, G. Jones, P.A. Racey, R.K. Wayne, Nature, 387 (1997)

22. A. Kiefer. Phylogeny of Western Palaearctic long-eared bats (Mammalia, Chiroptera, Plecotus) - a molecular perspective, $\mathrm{PhD}$ thesis (Gutenberg University in Mainz, 2007)

23. A. Kiefer, F. Mayer, J. Kosuch, O. Von Helversen, M. Veith, Mol. Phylogenet. Evol., 25 (2002)

24. D. Russo, G. Jones, Ecography 26 (2003)

25. I. Di Salvo, Attività e Distribuzione della Chirotterofauna in ecosistemi rurali della Sicilia Centro-Occidentale (Università degli Studi di Palermo, Dottorato in Biologia Animale XXIII ciclo, Sarà M., Parrinello N., 2011) 